\title{
Sam, a New Portable Long Duration Ultrasound Device (45 Subs)
}

\author{
David 0 Draper* \\ Brigham Young University, USA
}

*Corresponding author : David O Draper, Professor of athletic training and sports medicine, Brigham Young University, Provo, Utah, USA.

Received Date: December 14, 2018

Published Date: December 17, 2018

\section{Clinical Image}

The SAM (sustained acoustic medicine) is a small, portable device that delivers over 18,000 Joules of energy when 4 crystals are worn for 4 hours. This has been shown to decease trapezius myofascial pain, postoperative shoulder pain and low back pain with a herniated disk. The following is the results of a study comparing SAM and placebo on pain. (Figure 1)

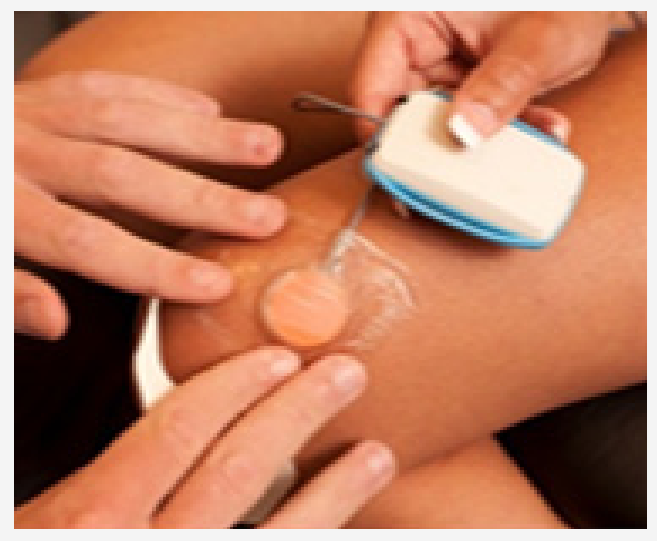

Figure 1: Preliminary version of Zetroz Device in knee.
The study

1. Double-blind, placebo controlled trial.

2. $\mathrm{N}=46$ patients with mild-moderate knee osteoarthritis.

3. 2 weeks baseline followed by 6 weeks treatment with SAM, self-applied to medial and lateral aspect of the knee. At least 4 treatments a week.

\section{Results}

1. Significant 2.5 VAS pain reduction in active vs. placebo group over 8-week study $(\mathrm{p}<0.003)$.

2. Significant 1.35 Weeks of daily reduction in pain vs. placebo group. $(\mathrm{p}<.001)$ Based upon the results of the study, SAM is effective at relieving osteoarthritis of the knee.

\section{Acknowledgement}

None.

\section{Conflict of Interest}

No Conflict of Interest. 